\title{
Ventrogluteal ve Dorsogluteal Bölgeye Uygulanan İntramüsküler Enjeksiyonların Kanama, Ağrı ve Hematom Açısından Karșılaștırılması
}

\author{
Comparison of Intramuscular Injections Applied on Ventrogluteal and Dorsogluteal Areas in the Way of \\ Bleeding, Pain and Hematoma
}

Emine APAYDIN ${ }^{1}$, Havva ÖZTÜRK ${ }^{2}$

\begin{abstract}
ÖZ
Yarı deneysel niteliğindeki bu çalışma, ventrogluteal ve dorsogluteal bölgeye uygulanan intramüsküler enjeksiyonları kanama, ağr1 ve hematom açısından karşılaştırmak amacıyla yapılmıştır. Araştırmanın evrenini, bir devlet hastanesinin acil ünitesi intramüsküler enjeksiyon birimine başvuran 840 hasta ve örneklemini ise, bu hastalardan güç analizi ile \%95 güven aralı̆̆ında, hesaplanan ve bu hastalar arasindan örnekleme alınma ölçütlerini karşıllayan 102 hasta oluşturmuştur. Veriler, Hasta Tanılama Formu, Hasta İzlem Formu, Ağrı Skalası, Opsite-Flexigrid Ölçüm Aracı, Hematom Alanı Gruplandırması ile toplanmıştır. Veriler yüzde, ortalama, t-testi, Pearson korelasyon analizi ile değerlendirilmiştir. Bulgulara göre hastaların dorsogluteal bölgelerine uygulanan intramüsküler enjeksiyon sonrası ağr1 ortalamas1 $3,68 \pm 1,54$, ventrogluteal bölgelerine uygulanan enjeksiyon

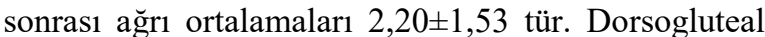
bölgelerine uygulanan intramüsküler enjeksiyon sonrasi kanama ortalamaları $0,42 \pm 0,66$, ventrogluteal bölgelerine uygulanan enjeksiyon sonrası kanama ortalamaları $0,20 \pm 0,32$ 'dir. Hastaların dorsogluteal bölgelerinde 48. saatte hematom oluşumu puanı $0,20 \pm 0,49, \quad 72$. saatte $0,32 \pm 0,67$, ventrogluteal bölgelerinde 48 . saatte $0,04 \pm 0,22, \quad 72$. saatte $0,07 \pm 0,29$ 'dur. Sonuç olarak ventrogluteal bölgeye uygulanan enjeksiyonlarda ağrı, kanama ve hematom oluşumunun dorsogluteal bölgeye uygulanan enjeksiyonlardan daha az görüldüğü saptanmıştır.
\end{abstract}

Anahtar Sözcükler: Ağrı, Dorsogluteal Enjeksiyon, Hematom, Kanama, Ventrogluteal Enjeksiyon

\begin{abstract}
This semi-experimental study is conducted to compare intramuscular injections applied on ventrogluteal and dorsogluteal sites in regards to bleeding, pain and hematoma. Population of the study was composed of patients who applied to the emergency care service of a state hospital. Sample group is consisted of 102 patients who meet the criteria of sampling with power analysis have $95 \%$ of confidence interval. Data were collected via Patient Information Form, Patient Observation Form, Pain Scale, Opsite-Flexigrid Measuring Tool and Grouping of Hematoma Area. The data were analyzed by the means of average, t-test, Pearson Correlation Coefficient. According to findings, after the intramuscular injection applied on dorsogluteal area, the average pain level of patients was $3.68 \pm 1.54$, after the injection on ventrogluteal area, the average pain level of patients was 2.20 \pm 1.53 . After intramuscular injection applied on dorsogluteal area, the average of bleeding was $0.42 \pm 0.66$, after the injection on ventrogluteal area, the average of bleeding was $0.20 \pm 0.32$. In 48 hours, the hematoma formation score on dorsogluteal area of patients was $0.20 \pm 0.49$, in 72 hours, it is $0.32 \pm 0.67$. In 48 hours, the hematoma formation score on ventrogluteal area of patients is $0.04 \pm 0.22$, in 72 hours, it was $0.07 \pm 0.29$. As a consequence, it was found that the pain, bleeding and hematoma formation after injections applied on ventrogluteal area were seen less than those of dorsogluteal area.
\end{abstract}

Key words: Bleeding, Dorsogluteal Injection, Hematoma, Pain, Ventrogluteal Injection

Çalıșma için ilgili Üniversitenin Etik Kurulu'ndan ve araștırmanın yürütüleceği kurumdan yazılı izin alınmıștır.

${ }^{1}$ Uzm. Hem. Emine APAYDIN, Hemşirelik Esasları ve Yönetimi, Giresun Üniversitesi Prof. Dr. A. İlhan Özdemir Eğitim Araştırma Hastanesi, Eğitim Birimi, hacettepeli_28@hotmail.com, ORCID: 0000-0002-6378-0636

${ }^{2}$ Prof. Dr. Havva ÖZTÜRK, Hemşirelik Esasları, Karadeniz Teknik Üniversitesi, Sağlık Bilimleri Fakültesi, havvaozturk@ktu.edu.tr, ORCID: 0000-0001-8515-6263

İletișim / Corresponding Author:

Emine APAYDIN

e-posta/e-mail:
Geliș Tarihi / Received:

Kabul Tarihi/Accepted:
17.09.2020

07.01 .2021 


\section{GIIRIŞ}

Hastaların tedavisinde önemli yer tutan ilaç uygulamaları hemşirelerin sorumlulukları arasında yer alır. Dolayısıyla sağl1k kurumlarında hastalarda tedavi için kullanılacak ilacı hekim yazdiktan sonra, doğru ilac1 hazırlayarak doğru hastaya, doğru zamanda, doğru yolla, doğru dozda uygulamak ve bireydeki etkilerini gözlemek hemşirelerin sorumluluğu altındadır. ${ }^{1}$

Hemşirelerin ilaç uygulamaları, ilaçların adları, etken maddeleri, uygulanma yolları, şekilleri, sınıflandırılması, etki mekanizması, yan etkileri, etkilerini değiştirebilen unsurlara dair temel bir bilgilere sahip olmaları gerekmektedir. Bununla birlikte anatomi, fizyoloji ve asepsi bilgisi, kritik düşünme, etik yargılama, karar verme ve iletişim becerisi de önemlidir. ${ }^{2}$

İlaçlar, ilacın özelliklerine ve vücutta istenen etkisine, hastanın fiziksel ve ruhsal durumuna göre değişmekle birlikte oral veya parenteral yollarla uygulanmaktadır. Her iki yolun da avantaj ve dezavantajları vardır. İlaçların ağız yoluyla verilmesi anlamına gelen oral yolla ilaçların uygulanması; en doğal, uygulaması kolay, riski ve maliyeti en az olan ilaç uygulama yoludur. ${ }^{3}$ Parenteral yol ise terapötik ajanların (ilaçların) sindirim sistemi dışındaki tüm yollarla verilmesidir. İlaçların enjeksiyon yolu ile uygulanmasını, sistemik emilim amacıyla beden dokularının içine verilmesini, yapılan enjeksiyonun adını, ilacın enjekte edildiği ya da uygulandığ bölge belirler. ${ }^{4,5}$

İntramüsküler enjeksiyonlar da parenteral ilaç uygulamalarının önemli bir parçasıdır ve s1k uygulanan hemşirelik becerilerindendir. İntramüsküler enjeksiyon, ilacın dermis ve subkutan dokunun altında bulunan kas tabakasına enjekte edilmesidir. Müsküler tabaka subkutan dokuya oranla daha çok kan damarı yapısına sahip olduğu için intramüsküler yolla verilen ilaçlar intravenöz yola göre daha yavaş, subkutan yola göre ise daha hızlı emilir. ${ }^{6,7}$ Verilecek ilaç miktarı, bölgelere ve vücut yapısına göre değişisir. Basit bir uygulama olarak düşünülmesine rağmen, intramüsküler enjeksiyon uygulaması azami dikkat ve özen ile yapılmadığı durumlarda çok ağır komplikasyonlara yol açabilmektedir. ${ }^{8}$ İntramüsküler enjeksiyonlara bağlı ortaya çıkan potansiyel komplikasyonlar abse, selülit, doku hasarı, nekroz, sinir yaralanmas1, granüloma, kas fibrozu ve kontraktür, ağrı, kanama, intravasküler enjeksiyon ve hematomdur. ${ }^{9,10} \mathrm{Bu}$ nedenle güvenli ilaç uygulamada temel ilkelerin yanı sıra bölge seçimi önem kazanır ve bölge sınırlarının çok iyi bilinmesi gerekir. İntramüsküler enjeksiyonlarda dorsogluteal ile ventrogluteal bölgelerdeki kanama oranı ve ağrı şiddetinin karşılaştırılması amaciyla, 2006 y1lında 67 hasta üzerinde bir araştırma yapılmıştır. $\mathrm{Bu}$ araştırmada hastaların ortalama ağrı şiddeti dorsogluteal bölgede 50,79 ve ventrogluteal bölgede 40,79 olarak belirlenmiştir. Aynı araştırmada ortalama kanama oran1 dorsogluteal bölgede 0,73 milimetre ve ventrogluteal bölgede 0,19 milimetre olarak bulunmuştur. Kas içi enjeksiyonlarda dorsogluteal bölgeye oranla daha hafif ağrı ve kanamaya sebebiyet vermesinden dolayı ventrogluteal bölgesinin seçilmesi önerilmiştir. ${ }^{11}$ Anatomik olarak doğru bölge olsa bile, doku yıkımını artıracağı ve ilaç emilimini engelleyeceği için irritasyon, inflamasyon, enfeksiyon ve ödem olan bölgelere enjeksiyon yapılmamalı; kemik, sinir ve kan damarlarının yerleşiminden uzak, yağ tabakasının ince olduğu bölge seçimine dikkat edilmelidir. Enjeksiyon bölgesi çok iyi belirlenmeli ve palpe edilmelidir. ${ }^{12,13}$

İntramüsküler enjeksiyonda kullanılan bölgeler; femoral bölge (rektus femoris kas1), laterofemoral bölge (vastus lateralis kası), deltoid bölge (deltoid kas1), dorsogluteal bölge (gluteus maksimus kası) ve ventrogluteal bölgedir (gluteus medius ve minimus kas1). Klinik uygulamalarda laterofemoral bölge hemșireler tarafından daha çok yenidoğanlarda ve 2 yaşın altındaki çocuklarda en iyi gelişmiş kas bölgesi olduğu için tercih edilen alandır. ${ }^{14,15}$ Deltoid bölge yalnızca çok az miktardaki (0,5-1 mililitre) ilaçların intramüsküler uygulaması ve aşılar 
İngiltere'de yapılan bir çalışmada da,

için kullanılmaktadır. ${ }^{13}$ Dorsogluteal bölge ise intramüsküler enjeksiyon uygulamaları için sinir yaralanması, kanama gibi bir çok risk taşımasına rağmen çok geniş bir bölge olduğu için hemşireler tarafından sıklıkla tercih edilen bir bölgedir. Hemşirelerin yataklı tedavi kurumlarında intramüsküler enjeksiyon uygulamalarına yönelik kanıta dayalı uygulamalar yerine geleneksel yaklaşımlarla sürdürdükleri saptanmıştır. ${ }^{16}$ Güneş ve arkadaşlarının yaptıkları araştırma sonuçları bu görüşü doğrular şekilde hemşirelerin \%60'ının intramüsküler enjeksiyon uygulamalarını yaparken çoğunlukla dorsogluteal bölgeyi kullandığını, yalnızca \%21,8'inin ventrogluteal bölgeyi tercih ettiğini saptamıştır. Oysa ki ventrogluteal bölge, büyük kan damarlarına ve sinirlere yakın olmadığından bütün hastalar için daha güvenli bir bölgedir.7,13,17 Chan et al. (2006) yaptıkları çalışmada dorsogluteal bölgeye yapılan intramüsküler uygulamada ilacin kasa ulaşma durumu radyolojik olarak incelenmiş ve 50 enjeksiyondan 34'ünde (\%68) ilacın kas dokusuna iletilemediği ve subkutan dokuda kaldığ1 belirlenmiştir. $^{18}$ Günümüzde intramüsküler enjeksiyon sonrası olas1 komplikasyonları en aza indirmek için 2-3 mililitre ilaç uygulamalarında ventrogluteal bölgenin kullanımı önerilmektedir. ${ }^{14,19,20}$

Ventrogluteal enjeksiyon sonrasinda damar sinir yaralanması dahil olmak üzere enjeksiyon tekniğinden kaynaklanan bölgesel komplikasyon bildiren bir rapora rastlanmamıştır. ${ }^{8,15,21-23}$ Dolayısıyla literatür bilgileri 1şı̆̆ında ventrogluteal bölge intramüsküler enjeksiyon uygulamak için en güvenli bölge olarak tanımlansa bile, yapılan çalışmalar hemşirelerin büyük bir oranının hala bu bölgeyi tercih etmedikleri, bu konudaki tutumlarını değiştirme konusunda isteksiz oldukları belirlenmiştir. ${ }^{20}$ hemşireler bu bölgeyi tercih etmeme nedeni olarak bölgenin anatomik yap1 itibari ile küçük olmasını, ventrogluteal bölgenin dorsogluteal bölge kadar güvenli olmadığını düşündüklerini, enjeksiyonu gluteus medius kasına yapabilmek için bölge tespiti konusunda kararsız kaldıklarını ifade etmişlerdir. Bununla birlikte bu bölgeye enjeksiyon uygulandiğı takdirde, hemşirelerin büyük bir kısmı hasta bireylere zarar verebileceklerini düşündüklerini belirtmektedir. ${ }^{20,24}$

Sonuç olarak literatür incelendiğinde, dorsogluteal ve ventrogluteal bölgeye yapılan enjeksiyon uygulamalarının etkilerini karşılaştırmak amacı ile yapılan çalışma sayısının kisıtlı ve ventrogluteal bölgenin avantajlarına rağmen dorsogluteal bölgenin en çok kullanılan bölge olduğu tespit edilmiştir. Oysa bu alanda daha çok kanıta dayalı araștırmalar yapılıp sağlık profesyonellerinde farkındalık oluşturmaya yönelik eğitim çalışmalarının yürütülmesi gerekmektedir. Dolayısıyla, konuya yönelik yürütülen çalışmalardan elde edilen sonuç ve önerilerle hangi bölgenin daha güvenli olduğuna dair elde edilen sonuçlar hemşirelerle paylaş1labilir, hemşirelerin doğru bölgeyi kullanma oranlarının artması, böylelikle verilen hizmetin kalitesinin yükseltilmesi, hasta memnuniyetlerinin artması, enjeksiyon sonrası görülen komplikasyonların azalması sağlanabilir.

$\mathrm{Bu}$ nedenle çalışma, Sağlık Bakanlığına bağlı bir devlet hastanesinin acil ünitesi enjeksiyon birimine intramüsküler enjeksiyon için başvuran hastaların dorsogluteal ve ventrogluteal bölgelerine uygulanan intramüsküler ilaç enjeksiyonlarını kanama, ağrı ve hematom açısından karşıllaştırmak amaciyla yapılmıştır.

\section{MATERYAL VE METOT}

\section{Araştırmanın Yeri ve Zamanı}

Araştırma, Giresun ilinde bir devlet hastanesinin intramüsküler enjeksiyon biriminde Ocak - Nisan 2017 ayları arasında yarı deneysel olarak yapılmıştır. 


\section{Araştırmanın Evreni ve Örneklemi}

Araştırmanın evrenini, acil ünitesi intramüsküler enjeksiyon birimine 4 aylık süreç içerisinde başvuran olan ortalama 840 hasta oluşturmuştur. Bu hasta sayısı, 2017 yılında hastane kayıtlarından geriye dönük saptanmış olup, araştırmanın veri toplama süreci (4 ay) dikkate alınarak belirlenmiştir. Araştırmanın örneklemi ise bu intramüsküler enjeksiyon birimine başvuran ortalama 840 hastadan güç analizi ile $\% 95$ güven aralığında, 0,5 etki büyüklüğü, $\% 80$ güç değeri ile hesaplanan ve bu hastalar arasından örnekleme alınma ölçütlerini karşılayan 102 hasta oluşturmuştur.

Araştırmaya kabul edilme ölçütleri;

- Hastanın en az iki kere intramüsküler enjeksiyon tedavisinin olmas1,

- Trombosit değerinin 150000 / milimetreküp ve üzerinde olması,

- APTT (Aktive Parsiyel Tromboplastin Zamanı) değerinin 20-40 saniye arasında olmas1,

- International Normalized Ratio (INR) değerinin 0,8-1,2 arasında olması (hastaların laboratuvar değerleri hastane modülünde yer alan geriye dönük tarama ile son 3 ay içerisindeki tahlillere bakılarak araştırmacı tarafından değerlendirilmiştir),

- Antikoagülan ilaç kullanmaması,

- Enjeksiyon bölgesinde skar, insizyon, lipodistrofi ve enfeksiyon bulgusunun olmamas1,

- Allerji öyküsünün olmamas1,

- 18-65 yaş aralığında olması,

- Araştırmaya katılmayı kabul etmesi,

- Dodex (Siyanokobalamin yani B12 vitamini içeren pernisiyöz anemi, hiperkrom makrositer anemi, nevralji, nevrit, siyatik tedavisinde kullanılan, 1 mililitrelik ampuller şeklinde, kırmızı renkli bir solüsyondur. Dodex tedavisinin seçilme nedeni acil ünitesi intramüsküler enjeksiyon birimine bu ilac1 yaptırmak için gelen kişilerin sik olması (aylık ortalama 111 kişi), dodexin sadece intramüsküler olarak uygulanabiliyor olması, tedavi protokolünün genellikle beş gün üst üste uygulama şeklinde olması böylece hastalara ve örneklem sayısına daha kolay ulaşılması ilacın tercih edilme nedenidir.) ampul 1 mililitre reçete edilmiş olmasıdır.

Araştırmaya kabul edilmeme ölçütleri;

- Enjeksiyon uygulaması için ikinci kez acil ünitesine gelmeyen hastalardır.

\section{Veri Toplama Araçları}

Verilerin toplanmasında, Hasta Tanılama Formu, Ağrı Skalası, Opsite-Flexigrid Ölçüm Aracı, Hematom Alanı Gruplandırması ve Hasta İzlem Formu kullanılmıştır.

\section{Hasta Tanılama Formu}

Araştırmacı tarafından oluşturulmuş olup çalışmaya katılmayı kabul eden hastaların yaşını, cinsiyetini, medeni durumunu, eğitim durumunu ve mesleğini içeren demografik özelliklerini ve hastanın klinik tanısını, sistemik hastalıklarını, laboratuvar değerlerini, kullandığı ilaçları, boyunu, kilosunu, beden kitle indeksini tanımlamaya yönelik özelliklerini içeren 13 sorudan oluşturulan bir formdur.

\section{Görsel Ăgrı Skalası}

Bir ucunda ağrı yok, diğer ucunda dayanılmaz ağrı yazan $10 \mathrm{~cm}$ 'lik bir cetvel üzerinde hastanın ağrı şiddetini işaretleyeceği şekilde tasarlanmış bir ölçektir. Hastaya bu iki uç arasında bulunan rakamlardan ağrısının şiddetine uygun olanı işaretlemekte özgür olduğu anlatılır. Kolay sinıflandırılabilmesi için 0-ağrı yok, 1-3 hafif ağrı, 4-7 orta şiddetli ve 8-10 şiddetli olarak ölçek sınıflandırılmıştır. Ağrı şiddetinin değerlendirmesinde diğer yöntemlere göre duyarlılığının yüksek olduğu ve uygulanan ağrı şiddetini saptama yöntemleri arasında güvenilir bir ölçüm arac1 olduğu belirtilmektedir. ${ }^{25,26}$ Skala sayıları bilen 5 yaşındaki çocuklardan itibaren erişkinlere kadar bütün yaş gruplarında uygulanmaktadır. ${ }^{27,28}$

\section{Opsite-Flexigrid Ölçüm Aracı}

Şeffaf yapışkan ve nem geçirgenliği olan rahat kullanımlı bir film örtüdür. OpsiteFlexigrid akrilik yapıştırıcı tabakası ile 
kaplanmış ince bir poliüretan membrandan oluşmuştur. Yapıştırıldıktan sonra maruz kalan doku üzerinden su buharı kaybinı azaltarak yaranın yüzeyinde nemli bir çevre oluştururken diş kontaminasyonu önlemektedir. Opsit Flexigrid, birinci veya ikinci derece yanıklar, ameliyat sonrası yaralar, küçük yaralanmalarda yüzeyel basınç bölgelerinin önlenmesi ve tedavisinde kullanılabilir. Üzerinde küçük kareler ve şeffaflığı nedeni ile hematom çapının ölçümünde de kullanılmaktadır. ${ }^{29,30}$

\section{Hematom Alanı Gruplandırması}

Şeffaf bant ile ölçülen hematom büyüklükleri iğnenin giriş yerinde nokta şeklinde renk değişikliği oluşmuşsa pinpoint=iğne ucu, $0,2-1 \mathrm{~cm}$ arasinda ise orta, 1 santimetreden büyükse büyük hematom olarak değerlendirilmiştir. ${ }^{31}$

\section{Hasta İzlem Formu}

İntramüsküler enjeksiyon yapılan hastalardan elde edilen verilerin kaydı için araştırmacı tarafindan oluşturulmuştur. Her hasta için ayrı ayrı oluşturulup enjeksiyon sonrası kanama, ağrı, 48. ve 72. saatte hematom değerlendirilerek bu forma kayıt edilmiştir.

\section{Veri Toplama Süreci}

Veri toplama sürecinde öncelikle hekim tarafindan Dodex ampul reçete edilen ve acil ünitesi enjeksiyon birimine başvuran hastalar çalışmaya alınmadan önce bilgilendirilmiş ve onamları alınmıştır. Daha sonra hastalara demografik bilgileri içeren Hasta Tanılama Formu araştırmacı tarafından uygulanmıştır. Tanilama formu doldurulduktan sonra enjeksiyon uygulaması gerçekleştirilmiştir. Enjeksiyon uygulaması; içerisinde iki sedye bulunan ve sadece enjeksiyon için kullanılan odada, hastaların mahremiyetini sağlamak için enjeksiyon sırasında perde kapatılarak uygulanmıştır. Hastaya yüzüstü yatar pozisyon verilip öncelikle enjeksiyon bölgesi değerlendirilmiştir. Daha sonra hekim tarafından reçete edilen ilaç araştırmacı tarafindan hastaya önce dorsogluteal bölgeye, ikinci kez acile başvurduğunda ise semptomların daha iyi ayırt edilebilmesi için diğer bacaktaki ventrogluteal bölgeye uygulanmıştır. Her iki enjeksiyon 90 derece açı ile intramüsküler enjeksiyon uygulama prosedürlerine uygun olarak ve standart olarak kullanılan $21 \mathrm{G}$ yeşil iğne ucu ile uygulanmıştır. Her enjeksiyon uygulanması sonrasinda bir adet steril gazlı bez bastırmadan enjeksiyon yeri üzerine yerleştirilmiştir ve kanamanın durması beklenmiştir. Sonra steril gazlı bez üzerinde bulunan kan lekesinin çapı milimetrik cetvel ile ölçülüp, kanama miktarı belirlenmiştir. $\mathrm{Bu}$ sonuç Hasta İzlem Formuna kayıt edilmiştir. Her enjeksiyon uygulanmasının hemen sonrasında ağrı skalası ile hastanın ağrı şiddeti ölçülmüştür. Literatürde kas içi enjeksiyonlarda hematom oluşumunun uygulamadan ne kadar süre sonra ortaya çıktığına ilişkin bir bilgiye rastlanmamakla birlikte, subkutan heparin uygulamalarından 48 saat sonra başladığı ve 72 saatten önce kaybolmadığ 1 belirtilmektedir. ${ }^{31} \mathrm{Bu}$ nedenle uygulanan her bir enjeksiyon bölgesi, uygulamadan sonraki 48 . ve 72 . saatlerde tekrar enjeksiyon için geldiklerinde toplam iki kez hematom yönünden takip edilmiştir. Eğer hematom oluşmuş ise hematomun üzeri polietilen milimetrik plastik film ile örtülüp hematomun büyüklüğü ölçülmüştür. Sonuçlar Hasta İzlem Formu'na kayıt edilmiştir. Elde edilen ölçüm farklılıklarına göre hematom alanı gruplandırılmıştır. Araştırmacı aynı hastanede hemşire olarak çalışmakla birlikte enjeksiyon biriminde çalışmamaktadır. Çalışmanın yürütüldüğü süre zarfinda birimde çalışmıştır ve bütün enjeksiyonlar uygulayan kişiden kaynaklanabilecek hataları en aza indirgemek adına araştırmacı tarafından yapılmıştır. Enjeksiyon sonrası hematom gelişen hastalardan görüntü alımı düşünülmesine rağmen, hastaların gönüllü olmaması ve mahremiyet açısından görüntü alınmamıştır.

\section{Araştırmanın Etik Yönü}

Araştırmanın yapılabilmesi için araştırma kapsamındaki hastane için Giresun İli Kamu Hastaneler Birliği Genel Sekreterliği'nden 02.11.2016 tarihinde yazılı izin alınmıştır. Ayrıca Karadeniz Teknik Üniversitesi T1p Fakültesi Klinik Araştırmalar Etik Kurul Başkanlığı'ndan 09.01.2017 tarihinde 24237859 nolu sayı ve 55 numara ile etik 
kurul izni alınmıştır. Araştırmada yer alan hastalara çalışmanın adı, amacı, planı, süresi ve kendisinden ne beklendiği, elde edilen verilerin nasıl ve nerede kullanılacağı açıklanmıştır. Çalışmaya katılma ya da katılmamaya karar vermede özgür oldukları, bilgi vermeyi reddetme hakkına sahip oldukları, çalışmayı herhangi bir noktada bırakabilecekleri açıklanarak istekli ve gönüllü olma ilkesine bağlı kalınmıştır. Hastalardan Hasta Onam Formu ile yazılı onam alınarak hastalar araştırmaya dahil edilmiştir. Hastaların olası problemler ve komplikasyon durumunda araştırmaciya ulaşabilmesi için araştırmacının telefonu ve iş yeri adresi verilmiştir.

\section{Verilerin Analizi ve Değerlendirilmesi}

Araştırmada elde edilen veriler SPSS (Statistical Package for Social Sciences) for Windows 22,0 programı kullanılarak analiz edilmiștir. Verilerin analizinde, hastaların demografik özelliklerini, hastalık ve ilaç durumlarını belirlemek için sayı, yüzdelik testleri, laboratuvar sonuçlarını tanımlamak ve ağrı, kanama ve hematom ölçüm sonuçlarını tanımlamak için ortalama ve standart sapma testleri kullanılmıştır. Normal dağılım için Kolmogrov ve Smirnov testleri yapılmıştır. Hastaların demografik özellikleri, hastalık ve ilaç kullanım durumları ile ağrı, kanama ve hematom ölçüm sonuçlarını karşılaştırmak için t-testi kullanılmıştır. Elde edilen bulgular \%95 güven aralığında, \%5 anlamlılık düzeyinde değerlendirilmiştir.

\section{Araştırmanın Sınırlılıkları}

$\mathrm{Bu}$ araştırmanın sonuçları sözkonusu hastaneye başvuran hastalar ile sınırlıdır. Ayrıca olası komplikasyonlardan sadece ağrı, kanama ve hematomun sorgulanmıştır.

\section{BULGULAR VE TARTIŞMA}

Hastaların \%33,3'ü 30 yaş ve altında, \%68,6's1 kadın, \%69,6's1 evli, \%38,2'si ilkokul mezunu ve \%32,4'ü ev hanımıdır. Ayrıca hastaların \%52,9'unun beden kitle indeksi normal kilo değerleri içindedir. Hastaların boyları ortalama 1,66 $\pm 0,06$ santimetre, kiloları ortalama $70,71 \pm 14,49$ kilogram ve beden kitle indeksleri ortalama $25,52 \pm 5,75$ dir.

Hastaların \%91,2'si B12 eksikliği tanısına sahiptir, \%61,8'inin herhangi bir sistemik hastalığ 1 yoktur ve \%69,6's1 herhangi bir ilaç kullanmamaktadır. Sistemik hastalığ 1 sahip olan hastaların ise \%30,8 hipertansiyon hastasidir ve \%29'u antihipertansif ilaç kullanmaktadır.

Hastaların hemoglobin değeri 13,47 $\pm 1,96$, hemotokrit değeri $39,92 \pm 5,59$, eritrosit değeri 4.58 \pm 0.54 , lökosit değeri 7,19 $\pm 1,54$, trombosit değeri $261,36 \pm 58,77$, APTT değeri $30,85 \pm 3,07$ ve INR değeri $1,03 \pm 0,23$ tür.
Hastaların dorsogluteal bölgesine uygulanan enjeksiyonlara ilişkin ağrı puan ortalamas1 3,68 $\pm 1,54$, kanama puan ortalamas1 $0,42 \pm 0,66,48$. saatteki hematom puan ortalamas $0,20 \pm 0,49$ ve 72 . saatteki hematon puan ortalamas1 $0,32 \pm 0,67$ dir. Ventrogluteal bölgeye uygulanan enjeksiyonlardaki ağrı puan ortalaması ise $2,20 \pm 1,53$, kanama puan ortalamas 1 $0,20 \pm 0,32$, 48. saatteki hematom puan ortalamas $0,04 \pm 0,22$ ve 72 . saat hematom

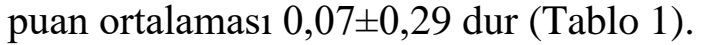

Aynı hastanın dorsagluteal ile ventrogluteal bölgelerine yapılan enjeksiyon uygulamaları karşılaştırıldığında, ağrı, kanama, 48. saatte hematom ve 72 . saatte hematom yönünden, ventogluteal bölge puan ortalamalarının dorsagluteal bölgeye göre daha düşük olduğu ve bulguların istatistiksel olarak anlamlı farklılık gösterdiği bulunmuştur ( $\mathrm{t}=10,382 ; \mathrm{p}=0,000 ; \mathrm{t}=3,377$; $\mathrm{p}=0,001 ; \quad \mathrm{t}=3,522 ; \quad \mathrm{p}=0,001 ; \quad \mathrm{t}=4,162$; $\mathrm{p}=0,000) \quad($ Tablo 1$)$. 
Tablo 1. Dorsogluteal ve Ventrogluteal Bölgelere Uygulanan İntramüsküler Enjeksiyonların Ağrı, Kanama ve Hematom Açısından Karşılaştırılması

\begin{tabular}{ccccc}
\hline $\begin{array}{c}\text { Enjeksiyonlara İlişkin } \\
\text { Sorunlar }\end{array}$ & $\begin{array}{c}\text { Dorsogluteal } \\
\text { Enjeksiyon }\end{array}$ & $\begin{array}{c}\text { Ventrogluteal } \\
\text { Enjeksiyon }\end{array}$ & t & $\mathbf{p}$ \\
\hline Ăgrı & $3,68 \pm 1,54$ & $2,20 \pm 1,53$ & 10,382 & 0,000 \\
Kanama & $0,42 \pm 0,66$ & $0,20 \pm 0,32$ & 3,377 & 0,001 \\
48.saatte hematom & $0,20 \pm 0,49$ & $0,04 \pm 0,22$ & 3,522 & 0,001 \\
72.saatte hematom & $0,32 \pm 0,67$ & $0,07 \pm 0,29$ & 4,162 & 0,000 \\
\hline
\end{tabular}

İntramüsküler enjeksiyonlar, hastalarda en fazla ağrı ve rahatsızlığa neden olan enjeksiyon ya da invazif girişimlerden biridir. $^{32}$ Bundan dolayı intramüsküler enjeksiyon uygulamasına yönelik bu çalışmada öncelikle hastanın ağrısı daha sonra hematom çapı ve kanama miktarı değerlendirilmiştir. Çalışmada, ventrogluteal bölgeye uygulanan intramüsküler enjeksiyonların dorsogluteal bölgeye uygulanan enjeksiyonlardan daha az ağriya neden olduğu saptanmıştır. Moharreri ve arkadaşlarının çalışmasında da bizim çalışmamızda olduğu gibi dorsogluteal bölgede hastaların $\% 83,5$ 'inin hafif veya orta şiddette, ventrogluteal bölgede \%88'inin hafif şiddette ağrı hissettiği ve \%9'unun ise hiç ağrı hissetmediği saptanmıştır. ${ }^{11}$ Kamats da büyük damar ve sinirlerden uzak olması, yağlı dokunun düzenli olmasından dolayı ağrı ve rahatsızlığın en az olduğu bölge olan ventrogluteal bölgenin tercih edilmesi gerektiğini önermektedir. ${ }^{33}$ Bununla birlikte intramüsküler enjeksiyona bağlı gelişen ağrıda, iğne girişinin yarattığı mekanik travmanın ve maddenin kas içine verilirken yarattığı ani basıncın da etkili olduğu bildirilmektedir. ${ }^{34}$ Literatürde, doğru ve güvenli bir intramüsküler enjeksiyon tekniğinin hastanın enjeksiyon sırasında daha az ağrı hissetmesine ve enjeksiyona bağlı gelișebilecek komplikasyonların önlenmesine yardımcı olduğu vurgulanmaktadır. ${ }^{23,35-37}$

İntramüsküler enjeksiyonlarda ağrı kadar önemli olan diğer bir komplikasyon da kanamadır. Kanama, kan damarlarından zengin olması nedeniyle dorsogluteal bölgede ventrogluteal bölgeye göre daha fazla görülmektedir. ${ }^{3}$ Ayrıca kanama APTT, trombosit, INR değerlerinin normal sınırlarda olmamasından da etkilenmektedir. ${ }^{38}$
Araştırmamızda hastaların bu laboratuvar değerleri ortalamas1 normal sınırlarda olmasına rağmen dorsogluteal bölgeye uygulanan enjeksiyonlar sonrasi kanama ortalamaları ventrogluteal bölgeye göre istatistiksel olarak daha yüksek saptanmıştır. Benzer şekilde yapılan bir çalışmada, hastaların ventrogluteal bölgelerinde gelişen kanama miktarı dorsogluteal bölgeye göre daha düşük saptanmıștır. ${ }^{11}$ Çünkü, dorsogluteal bölgenin ventrogluteal bölgeye göre damarlardan zengin olması nedeniyle bu bölgede enjeksiyon sonrası kanamanın daha çok geliştiği belirtilmektedir. ${ }^{32}$

Araştırma kapsamında değerlendirmeye alınan diğer bir komplikasyon olan hematoma bakıldığında, dorsagluteal bölge enjeksiyonları sonrası 48 . ve 72 . saatlerde gelişen hematom puan ortalamalarının ventrogluteal bölgeye göre daha yüksek olduğu belirlenmiştir. $\mathrm{Bu}$ durum, dorsogluteal bölgede yağ ve kas dokusunun daha kalın olması ve ilacın kas dokusuna iletilemeyip subkutan dokuda kalması ile ilişkilendirilmektedir. ${ }^{21}$ Ancak, ventrogluteal bölgede kas kalınlığı fazla olmayıp daha geniş bir alana yayıldığından dolayı ilacın kas tabakasına ulaşması daha kolaydır. ${ }^{18}$ Güneş ve arkadaşlarının yaptıkları çalışmada, araştırma kapsamına alınan bireylerin ventrogluteal ve dorsogluteal enjeksiyon bölgesindeki subkutan doku kalınlığ1 karşılaştırılmış, ventrogluteal bölgede $25,4 \pm 13,4$ milimetre ve dorsogluteal bölgede $26,3 \pm 11,7$ milimetre olduğu saptanmıştır. ${ }^{39}$ $\mathrm{Bu}$ sonuçlara göre dorsogluteal bölgedeki subkutan doku kalınlığının daha fazla olduğu görülmektedir. Yine intramüsküler enjeksiyon uygulamalarında yağ doku derinliğinin saptanmasına yönelik 100 erişkin birey arasında yapılan bir başka araştırmada, 
ventrogluteal bölge yağ dokusu derinliği ortalama 19 milimetre bulunurken, dorsogluteal bölge yağ doku derinliği ortalama 32 milimetre olarak saptanmıştır. ${ }^{40}$
$\mathrm{Bu}$ sonuçlar, ventrogluteal bölgeye uygulanan intramüsküler enjeksiyonlarda hematomun daha az görülmesini destekler şekildedir.

\section{SONUÇ VE ÖNERÍLER}

Sonuç olarak hemşireler ağrı, kanama ve hemotomun daha az gözlenmesi nedeni ile intramüsküler enjeksiyon uygulamalarında öncellikle ventrogluteal bölgeyi tercih etmelidir. Hastaların dorsagluteal ile ventrogluteal bölgelerine yapilan enjeksiyon uygulamaları ağrı, kanama ve hematom açısından karşılaştırıldığında, ventrogluteal bölgeye uygulanan enjeksiyondaki ağrı $(\mathrm{t}=10,382 ; \mathrm{p}=0,000)$, kanama $(\mathrm{t}=3,377 ; \mathrm{p}=0,001), \quad 48$. saatteki hematom $(t=3,522 ; p=0,001)$ ve 72 . saatteki hematom $\quad(\mathrm{t}=4,162 ; \mathrm{p}=0,000)$ puan ortalamaları, dorsagluteal bölgeye yapılan enjeksiyonun ağr1, kanama ve hematom puan ortalamalarından daha düşüktür ve bu bulgular istatistiksel olarak anlamlıdir. Bununla birlikte yapılan enjeksiyonlarda bölge seçimi yapılırken beden kitle indeksi, laboratuvar değerleri, bölgenin yağ dokusu gibi bireysel faktörler göz önünde bulundurulmalidir.

Bu sonuçlar doğrultusunda;

- Tüm hemşirelik eğitimlerinde, enjeksiyon bölgesinin seçiminde ventrogluteal bölgenin dorsogluteal bölgeye bir alternatif olarak değil, tercih edilmesi gereken ilk uygulama bölgesi olarak vurgulanmas1,
- Konuya ilişkin akademik yayınların sonuçlarının sahada çalışan hemşirelere hizmet içi eğitimlerle bildirilmesi, hemşirelerin ventrogluteal bölgeye enjeksiyon uygulamasına yönelik güvenin artırılmas1,

- Özellikle ventrogluteal bölge ve diğer intramüsküler enjeksiyon uygulamalarına yönelik komplikasyonların oluşmaması için hemşirelerin simulasyon eğitimlerinden yararlanmasının sağlanması,

- İntramüsküler enjeksiyona ilişkin girişimlerde kanıta dayalı gelişmelerin dikkatle izlenmesi, bu alanda yapılan çalışma sayısının artırılması ve yapılması planlanan çalışmaların desteklenmesi,

- Hemşirelik öğrencilerinin ders programlarında uygulamaya ilişkin bilgilerin güncellenmesi ve bu konunun öneminin anlatılması,

- Ventrogluteal bölgenin dorsogluteal bölgeye göre üstünlüğünün kanıtlanmış olmasının yanında bu bölgeye yönelik araştırmaları laterofemoral bölge ile de karşılaştırılarak avantaj ve dezavantajlarının ortaya konması önerilmektedir.
1. Ak, D. (2000). Dahiliye ve Yoğun Bakım Ünitelerinde Çalışan Hemşirelerin İlaç Uygulamalarına Yönelik Durum Analizi.” Marmara Üniversitesi Sağlık Bilimleri Enstitüsü, Yüksek Lisans Tezi, İstanbul.

2. Lynn, P. (2015). Taylor's Clinical Nursing Skills: A Nnursing Process Approach.” Ankara: Nobel Akademik Yayıncilik.

3. Karabacak, B.G. (2010). Sağlığın Değerlendirilmesi, Hasta Bakım ve Takibi. İstanbul: Nobel Tıp Kitabevleri.

4. Atalay, M. (1997). İlaç Uygulamaları İçinde Hemşirelik Esasları El Kitabı. İstanbul: Birlik Ofset Ltd. Şti.

5. Harkreader, H. and Hogan, M.A. (2000). Fundamentals of Nursing Caring and Clinical Judgement. USA.
6. Craven, R, Hirnle, C. ve Jensen, S. (2015). Hemşirelik Esasları: İnsan Sağlığı ve Fonksiyonları. Ankara: Palme Yayıncilik.

7. Akça Ay, F. (2011). Sağlık Uygulamalarında Temel Kavramlar ve Beceriler. Adana: Nobel Kitabevi.

8. Nicoll, L and Hesby, A. (2002). "Intramuscular Injections: An Integrative Research Review and Guidelines for Evidence-Based Practice”. Applied Nursing Research, 16 (2), 149-162.

9. Elizabeth, H. and Winslow, R.N. (1996). "The Right Site for I.M Injections". American Journal of Nursing, 96 (4), 53. 
10. Mayer, M. and Romain, O. (2001). "Sciatic Paralysis After A Buttock Intramuscular Injection in Children: An Ongoing Risk Factor". Arch Pediatr, 8 (3), 321-323.

11. Mohareri, A.R, Nasırı, H, Jahanshahı, M, Rahmanı, H, Abdollahi, A. and Rabiei, M. (2007). "The Comparıson of Pain Intensity and Rate of Bleeding in Intramuscular Injection in Dorsogluteal and Ventrogluteal Area". Journal of Gorgan University of Medical Sciences, 9 (3 (23), 37 41.

12. Potter, P.A. and Perry, A.G. (2009). Fundamentals of Nursing. Philadelphia.

13. Taylor, C.R, Lillis, C, Lemone, P. and Lynn, P. (2011/a). Fundamentals of Nursing: The Art and Science of Nursing Care. Philadelphia: Lippincott Williams and Wilkins.

14. Robinson, M.W. (2010). "Guide to Intramuscular Injections in Newborns". Nursing Made Incredibly Easy, 8 (5), 14-17.

15. Rodger, M.A. and King, L. (2000). "Drawing Up and Administering Intramuscular Injections: A Review of Literature". Journal of Advanced Nursing, 31 (3), 574-582.

16. Kuyurtar, F, Altıo, M, Karabel, Z. ve Kul, S. (2006) "Hemșirelerin İntramuskuler Enjeksiyon Hazırlık, Bölge Seçimi ve Uygulamaya Yönelik Bilgileri”. Yayınlanmamış Araştırma.

17. Aștı, T. ve Karadağ, A. (2014). Hemşirelik Esasları Hemşirelik Bilimi ve Sanatı. İstanbul: Akademi Yayınları.

18. Chan, V.O, Colville, J, Persaud, T, Buckley, O, Hamilton S. and Torreggiani, W.C. (2006). "Intramuscular Injections Into The Buttocks: Are They Truly Intramuscular". European Journal of Radiology, 58 (3), 480-484.

19. Small, S.P. (2004). "Preventing Sciatic Nerve Injury From Intramuscular Injections: Literature Review". Journal of Advanced Nursing, 47 (3), 287-296.

20. Donaldson, C. and Green, J. (2005). "Using The Ventrogluteal Site For Intramuscular Injection". Nurs Times, 101 (16), 36-38.

21. Potter, P.A, Perry, A.G, Stockert P. and Hall A. (2013). Fundamentals of Nursing. Canada: Mosby.

22. Kara, D, Uzelli, D. and Karaman, D. (2015). "Using Ventrogluteal Site in Intramuscular Injections is a Priority or an Alternative?". International Journal of Caring Sciences, 8 (2), 507-513.

23. Hopkins, U. and Arias, C.Y. (2013). "Large-Volume IM Injections: A Review of Best Practices". Oncology Nurse Advisor, 4, 32-37.

24. Greenway, K. (2004). "Using The Ventrogluteal Site For Intramuscular Injection”. Nurs. Stand, 18 (25), 9-42.

25. Cline, M.E, Herman, J, Show, F. and Marton, R.D. (1992) "Standardization of The Visual Analoque Scale". Nurse Research, 41 (6), 378-379.

26. Collins, S.L, Moore, A.R. and Mc Quay, H.J. (1997). "The Visual Analoque Pain Intensity Scale: What Is Moderate Pain In Milimetres?”. Pain, 72, 95-97.

27. Breivik, H. (2017). "Patients Subjective Acute Pain Scales (VAS, NRS) are Fine; More Elaborate Evaluations Needed for Chronic Pain, Especially in the Elderly and Demented Patients". Scandinavian Journal of Pain, 15, 73-74.

28. Berghmans, J.M, Poley, M.J, Van der Ende, J, Weber, F, Van de Velde, M, Adriaenssens, P, Himpe, D, Verhulst, F.C. and Utens, E. (2017). "A Visual Analog Scale to Assess Anxiety in Children During Anesthesia Induction (VAS-I): Results Supporting Its Validity in A Sample of Day Care Surgery Patients. Paediatric Anaesthesia, 27 (9), 955-961.
29. Cengiz, Z. (2014). Subkutan Heparin Kullanan Hastalarda Abdominal ve Deltoid Bölgelerin Ağrı, Hematom ve Ekimoz Gelişimi Açısından Karşılaştırılması. İnönü Üniversitesi Sağlık Bilimleri Enstitüsü, Yüksek Lisans Tezi, Malatya.

30. Öçal, H. (2012). Kas İçi Enjeksiyonlarda Ağrı, Kanama ve Hematom Gelişimi Açısından Dorsogluteal ve Ventrogluteal Bölgelerin Karşılaştırılması. Marmara Üniversitesi Sağlık Bilimleri Enstitüsü, Yüksek Lisans Tezi, İstanbul.

31. Akyol, A.D. (1998). "Subkutan Heparin Uygulamasında Farklı Lokalizasyon ve Uygulamaların Hematom Oluşumuna Etkisi İle Hematomun Giderilmesinde Buz Uygulaması Etkinliğinin İncelenmesi”. Ege Üniversitesi Sağlık Bilimleri Enstitüsü, Doktora Tezi, İzmir.

32. Ünal, K.S. (2010). "Emla Kreminin Intramüsküler Sefalosporin Uygulamasında Ağrıyı Azaltmadaki Etkinliğinin İncelenmesi”. Atatürk Üniversitesi Sağlık Bilimleri Enstitüsü, Yüksek Lisans Tezi, Erzurum.

33. Kamats, K. (2005). "Ventrogluteal Dorsogluteal Sites For IM Injections". Summer Research Journal Suny College at Brockport, 10, 9.

34. Mitchell, J.R. and Whitney, F.W. (2001). "The Effect Of Injection Speed On The Perception Of Intramuscular Injection Pain”. AAOHN Journal, 49 (6), 286-292.

35. Güneş Yapucu, Ü, Zaybak, A, Biçici, B. ve Çevik, K. (2009). "Hemșirelerin Intramüsküler Enjeksiyon İșlemine Yönelik Uygulamalarının İncelenmesi”. Atatürk Üniversitesi Hemşirelik Yüksekokulu Dergisi, 12 (4), 8490.

36. Gülnar, E. ve Çalışkan, N. (2014). "Hemşirelerin Ventrogluteal Bölgeye Intramüsküler Enjeksiyon Uygulamasına Yönelik Bilgi Düzeylerinin Belirlenmesi”. Dokuz Eylül Üniversitesi Hemşirelik Fakültesi Elektronik Dergisi, 7 (2), 70-77.

37. Yavuz, E.D. ve Karabacak, Ü. (2012). "İntramüsküler Enjeksiyonda Neden Ventrogluteal Bölgeyi Tercih Etmeliyiz?’. Hemșirelikte Araștırma Geliștirme Dergisi, 13 (2), 81-88.

38. Özdilli, K. ve Özhan, F. (2008). Hemşirelik Bakımında İlke Ve Uygulamalar. Ankara: Alter Yayıncılık.

39. Güneş, Y.Ü, Zaybak, A. ve Tamsel, S. (2008). "Ventrogluteal Bölgenin Tespitinde Kullanılan Yöntemin Güvenirliğinin İncelenmesi”. Cumhuriyet Üniversitesi Hemşirelik Yüksekokulu Dergisi, 12 (2), 14-25.

40. Nispet, A.C. (2006). "Intramuscular Gluteal Injections İn The İncreasingly Obese Population”. British Medical Journal, 332 (7542), 637-638. 